Western University

Scholarship@Western

Department of Economics Research Reports

Economics Working Papers Archive

1973

\title{
A Regional Model for Planning Public Investment in Education
}

Peter J. Kuch

Follow this and additional works at: https://ir.lib.uwo.ca/economicsresrpt

Part of the Economics Commons

Citation of this paper:

Kuch, Peter J.. "A Regional Model for Planning Public Investment in Education." Department of Economics Research Reports, 7304. London, ON: Department of Economics, University of Western Ontario (1973). 
Research Report 7304

A REGIONAL MODEL FOR PLANNING PUBLIC

INVESTMENT IN EDUCATION

BY

Peter J. Kuch *

* This paper is based on research done under a project funded by the Economic Development Division of the U.S. Department of Agriculture's Economic Research Service. 


\section{INTRODUCTI ON}

The primary purpose of this paper is to present a model that would be useful in planning the efficient development of the educational infrastructure within a region. Of necessity, such a model must be primarily concerned with the problem of how one allocates an exogenously fixed set of resources among a collection of different educational programs. In addition, it is desirable that it deal with such related issues as: How does one choose among competing educational technologies? What total amount of resources should be devoted to education within the region? How much reliance should be placed upon training activities external to the region? In order to answer these questions a model is required that can describe the entire spectrum of training activities available to the region and then can select among them, on the basis of the social benefits they generate and the social costs they impose, to produce an optimal configuration of future curricula offerings.

The model that is set out here is an attempt to fulfill these requirements. It is a multi-period linear programming model that maximizes the sum of the net social benefits associated with each educational activity, subject to a series of endogenous stock and flow constraints, exogenous resource constraints (which together with the endogenous constraints describe the prevailing educational technology), and an assortment of boundary and terminal conditions. ${ }^{1}$ The social benefits generated by each educational activity are approximated by the present value of the incremental lifetime

$1_{\text {The model }}$ is an outgrowth of the highly aggregative national educational planning models devised for Argentina by Irma Adleman and for Nigeria and Greece by Samuel Bowles. Irma Adleman, "A Linear Programming Model for Educational Planning: A Case Study of Argentina," in The Theory 
earnings that can be expected to result from undergoing that training.

The next section of the paper will deal with the justification for using a linear-programming formulation. This will be followed by a sectian describing the model itself, and a section that briefly discusses its application.

JUSTIFICATION FOR THE MODEL

The Planning Problem

If the educational planning problem is viewed as the search for a configuration of curricula offerings that, given the limited resources available to the educational system, generates the most social benefits, we are led directly to some form of optimization model. This problem calls for an optimization model in the sense that we are attempting to maximize some function. of the net social benefits produced by the educational activities subject to the constraints imposed by the scarcity of available resources and the production characteristics of education itself.

Why not simply maximize the volume of education output directly, subject to a cost constraint? Education does not produce a homogeneous output. In a sense, education produces joint products. The output of the education process has at least three dimensions--it produces a variety of cognitive skills; it engenders attitudes toward work and authority and generally transmits socially accepted values; and it performs the socially useful screening function of classifying students according to their

and Design of Economic Development, Irma Adleman and Erik Thorbeck, eds. (Baltimore: Johns Hopkins University Press, 1966), pp. 385-417. Samuel Bowles, Planning Educational Systems for Economic Growth (Cambridge, Massachusetts: Harvard University Press, 1969). 
$\equiv \quad$ ability and motivation. ${ }^{1}$ This multiplicity of outputs creates the problem of adding dissimilar units.

Since each type of formal training produces a distinctly different mix of joint outputs, and since each education activity almost by definition has a different inherent production function, the constrained maximization of the aggregate output of a collection of different education activities is not feasible. The alternative approach of optimizing each activity separately still faces the problem of the multiplicity of output dimensions, and does not seem to offer the planner any guidance on how to choose among activities.

The way around this impasse lies in measuring each educational output according to a common scale. If society values each educational output according to its productivity in terms of goods and services, and if it is assumed that each worker is paid the value of his marginal product, the wage an individual earns is a measure of the value of the bundle of educational outputs he possesses.

It follows that the present value of the lifetime income stream the graduate of an educational activity could expect to earn is the measure of the social value of all of the education he has thus far undergone plus the value of his raw labour. Thus, the difference between the present value of the lifetime earnings a student could expect to receive upon completing a particular curriculum and the present value of the alternative earnings

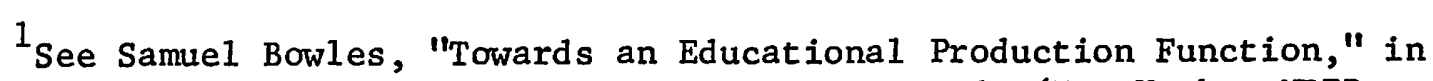
Education, Income and Human Capital, W. Lee Hansen, ed. (New York: NBER, 1970), pp. 1-70; Herbert Gintis, "Education Technology and the Characteristics of Worker Productivity," AER, Vol. LXI, No. 2, 1971, pp. 266-79; Ivar Berg, Education and Jobs: The Great Training Robbery (New York: Praeger Publishers, 1970). Paul Taubman and Terence J. Wales are currently investigating the importance of this screening dimension in a study sponsored by the NBER. 


\section{$-4-$}

stream he could have expected had he not enrolled in it, is the gross social value, per student, generated by this particular education activity. If the present value of the direct costs necessitated by the student's attendance is then subtracted from the incremental lifetime earnings stream, the difference is a measure of the net social benefits produced per student trained in this activity. The comparison of these net social benefits per student provides the planner with a means of choosing among alternative education activities.

To be sure, not all of the outputs of education are paid the value of their marginal products; there are externalities, discrimination and labour immobility. In fact, some of the outputs of education are not even factors of production; they must be viewed as consumption goods. Therefore, the incremental lifetime earnings associated with a training activity merely approximate the lower limit of the value of the bundle of outputs it produces, but as such, it is a useful starting point for planning purposes.

\section{The Subsequent Emigration of Students}

The regional approach to education planning raises the issue of how one treats the young people who subsequently emigrate from the region that financed their studies. Should the earnings generated by their education appear as positive entries into the planner's objective function, or are the resources committed to their education wasted from the point of view of the region $?^{1}$ It would seem that purely from the perspective of human capital accumulation and regional economic growth the benefits associated with

${ }^{1}$ Insofar as there is an offsetting inflow of students of like age and training, the planner can in general ignore the problem. But a poor rural area is generally faced with a net outflow of young people, the better educated being the most likely to leave. 
the education of these students are lost to the region. However, a large segment of the region's population, consisting at least of the school-age children and their parents, would take an opposing position. They are not primarily concerned with the benefits received by the region, but with the benefits that ultimately accrue to the student himself. They desire a school system that will simultaneously maximize the benefits the student receives over his lifetime, while minimizing the private costs of his education. Residence after graduation will only have a significant effect on their decision-making, and hence, on their political activity, insofar as it affects the total quantity of benefits the student will in the end receive from his education.

If one takes the position that the earnings received by emigrants should be ignored, the benefit stream generated by each education activity must be reduced to take account of the net outflow of the graduates of that type of activity. The modifications this would imply for the planner's objective function would probably lead him to drop from consideration any curriculum that tended to greatly increase labour mobility, regardless of its effect on the students' prospective earnings. This position and its implications for education planning are probably incompatible with the prevailing sentiment in most economically-underprivileged regions. Furthermore, it is far from clear that the optimal strategy for improving the welfare of the inhabitants of such regions involves discouraging emigration by limiting educational opportunities. Given these reasons, and the greater inherent simplicity of application implied by the alternative position, the benefits accruing to all of the graduates of the region's schools are treated as accruing to the region, regardless of the graduates' ultimate place of residence. 
The Assumption of Linearity

It seems reasonable to formulate the planning problem as a linearprogramming problem so long as the assumptions of linearity, with respect to both the objective function and the constraints, are in conformity with what is known about the relationship of earnings to the output of trained manpower and the characteristics of educational technology.

\section{Linearity in the Objective Function}

In relation to the proposed model, a linear objective function implies a constant marginal return to additional output from each educational activity. In other words, the net social return attributable to each student who passes through a curriculum is invariant with the number of students who preceded him. Thus, if the social benefits are measured by the incremental expected lifetime earnings associated with each type of training, the use of a linear objective function requires that the relative earnings accruing to different types of trained manpower be invariant with the educational composition of the labour force. 1

There is evidence to indicate that this has been true historically in the United States. Griliches has found that the relative mean incomes of U.S. males by schooling category has remained fairly constant over the period 1939 to 1966, and also that the relative mean incomes of Professional and Technical Workers to Operatives and Kindred Workers in the U.S. has remained constant over the period 1947 to $19640^{2}$ Herman Miller has

${ }^{1}$ Alternatively, it can be assumed that the regional population is such a small fraction of the total labour force that changes in its composition will have an insignificant effect on the educational composition of the total labour force, and hence, on relative earnings in the economy as a whole. 
compared the relative lifetime earnings of elementary-school graduates, high-school graduates, and college graduates during the period 1939 to 1961; he also found that the relative lifetime earnings of these education classes has remained fairly constant over this period. ${ }^{1}$

This observed constancy of relative earnings may be due to compensating shifts in the short-run demand for labour possessing different sorts of education which just offset shifts in their relative supply. While reasonable arguments can be made in support of this explanation, 2 little empirical evidence can be mustered on its behalf. However, there is a reasonable amount of empirical evidence supporting a more general explanation of constant relative lifetime earnings, namely that the longer-run aggregate demand functions for specific types of labour are highly elastic. ${ }^{3}$ Ceteris paribus, one expects the elasticity of demand for a factor of production to be greater, the greater the elasticity of substitution

Functions and Growth Accounting," in Education, Income and Human Capital, W. Lee Hansen, ed. (New York: NBER, 1970), p. 88 .

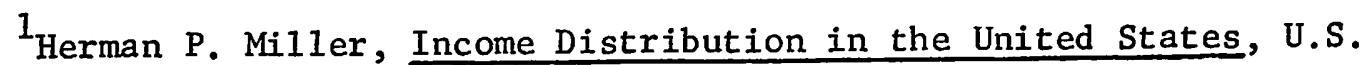
Bureau of the Census, A 1960 Census Monograph (Washington, D.C.: U.S. Government Printing Office, 1966), p. 163.

2 See Zvi Griliches, "Notes on the Role of Education in Production Functions and Growth Accounting," p. 104; Finish Welch, "Education in Production," Journal of Political Economy, Vo1. 78, No. 1, January/February 1970, pp. 37-39; and Ivar Berg, Education and Jobs: The Great Training Robbery (New York: Praeger Publishers, 1970).

3 The second explanation subsumes the first. Compensating shifts in the short-run demand function for a given sort of labour will tend to make the long-run demand function for this labour very elastic. 
between it and other factors. Ignoring non-labour factors of production, there is both direct and indirect evidence to support the proposition that there is a high elasticity of substitution between different types of labour. Turning to the indirect evidence first, if one ignores certain occupations like the law and medicine which have statutory educational requirements, there do not seem to be formal schooling requirements for the performance of most jobs. ${ }^{1}$ This suggests that at least one reason to expect a high elasticity of substitution between labour with different educational backgrounds is the absence of unique technologically determined schooling requirements for the acquisition of particular skills. This will be true insofar as many curricula produce a similar basic core of skills, or insofar as the major economic functions of formal schooling are the inculcation of certain attitudes toward work and the screening of potential job candidates according to their innate abilities and work discipline. In both of these cases, most of the occupation-specific skills are learned on-the-job. Turning to the direct evidence of a high elasticity of substitution, Bowles estimated the elasticity of substitution between three classes of labour--0 to 7 years of school, 8 to 11 years of school, and 12 or more years of school--using cross-sectional data from twelve countries. ${ }^{2}$ The

$1_{\text {Bowles looked at twenty-odd occupational groups (including: civil }}$ engineers, electrical engineers, designers and draftsmen, electricians and carpenters) and in no case did the distribution of workers by education or relationship of earnings to years of schooling correspond to what one would have expected from the existence of specific educational requirements for the occupation. Samuel Bowles, Planning Educational Systems for Economic Growth (Cambridge, Massachusetts: Harvard University Press, 1969), p. 54.

2 Samuel Bowles, Planning Educational Systems for Economic Growth, p. 45. Bowles' estimate of the elasticity of substitution between the first and second classes was 12.0 , between the first and third classes was 6.4 , and between the second and third classes was 202.0. Each estimate is significantly greater than 3 at the 99 percent significance level. 
elasticities are significantly greater than 3 and are consistent with the hypothesis that there is no strong negative relationship between relative wages and relative factor quantities. Marcelo Selowsky, using the 1:1000 Sample of the 1960 U.S. Census, estimated the elasticity of substitution among various pairs of types of labour, classified by years of schooling, in fifty-nine U.S. manufacturing industries. His results for the nine cases he estimated showed the elasticity of substitution to be significantly greater than 6 at the 95 percent significance level. ${ }^{1}$ Bowles has also used U.S. time-series data to estimate the elasticity of substitution between his education classes. The estimated elasticities were at least as high as those estimated using international cross-sectional data. ${ }^{2}$ Zvi Griliches' estimates of aggregate production functions for U.S. agriculture and manufacturing, using regional data, also tend to support the hypothesis of an infinite elasticity of substitution between different types of labour. ${ }^{3}$ Thus, there seems to be a significant amount of evidence to support highly elastic long-run demand functions for different types of labour defined in terms of level of schooling and therefore, a constancy of their relative earnings. It also seems reasonable to suppose that similar forces are at work between different types of schooling, and that as a result, the

$1_{\text {Reported by Bowles in Planning Educational Systems for Economic }}$ Growth, p. 55 .

${ }^{2}$ Samuel Bowles, "Aggregation of Labor Inputs in the Economics of Growth and Planning: Experiments with a Two-Level CES Function," Journal of Political Economy, Vo1. 78, No. 1, January/February 1970, p. 75.

${ }^{3}$ Zvi Griliches, "Notes on the Role of Education in Production Functions and Growth Accounting," p. 86. 
long-run demand functions for different types of labour, defined by type of curriculum studied as well as level of schooling, would also be highly elastic. Even if this were not completely true, provided we are dealing with one sma11 region supplying labour to a national market, given the high mobility of educated labour, it seems safe to assume that the aggregate demand functions facing the different sorts of trained labour produced by the region in question are highly elastic. On balance then, it seems reasonable to assume constant relative lifetime earnings and to use a linear objective function.

\section{Linearity in the Constraints}

The use of linear input constraints implicitly assumes that one is dealing with technologies that are best described by fixed-coefficient production functions. ${ }^{1}$ An important question, therefore, is whether such an assumption is permissible in describing the production of trained manpower.

Very little is known about the characteristics of educational production functions. There have been few empirical attempts to specify an educational production function. Those attempts that have been made have tended to measure output in terms of achievement test scores. ${ }^{2}$ Such an

$1_{\text {These are production functions that take the form }}$ $Y=\min \cdot\left[\frac{X_{1}}{a_{1}}, \frac{x_{2}}{a_{2}}, \ldots, \frac{X_{n}}{a_{n}}\right]$, where $a_{i}$ is the number of units of $x_{i}$ required to produce one unit of $Y$.

2 See for example Samuel Bowles, "Towards an Educational Production Function," and Erik C. Hanushek, "The Education of Negroes and Whites," an unpublished Ph.D. dissertation, MIT, 1968. 
output measure is of limited usefulness in a regional planning model, and measures only one dimension of educational output.

From a purely pedigogical point of view, the potential degree of substitution between inputs is probably quite large. ${ }^{1}$ It appears to be possible to reduce the number of teachers per pupil or teacher quality by increasing the use of audio-visual equipment, using better texts or using team teaching methods. Physical space requirements can also be altered by using different instructional methods. But despite this seemingly large range of potential substitutions among educational inputs, one does not observe a significant degree of substitution in practice. Educators in any one institution or type of institution seem to be in agreement about the optimal input mix for any particular curriculum. They seem to religiously follow certain norms, of uncertain origin, in allocating teachers' time, physical space, and financial resources. They use the same norms in planning their future resource requirements and in justifying their budgetary requests to legislative bodies. 2 Whatever their theoretical rationale, ex post they behave as though they are operating with fixed-coefficient production functions. of course, this situation may result from the fact that the production of different types of education involves production functions that are homogeneous of degree one and that ultimately use only one primary factor

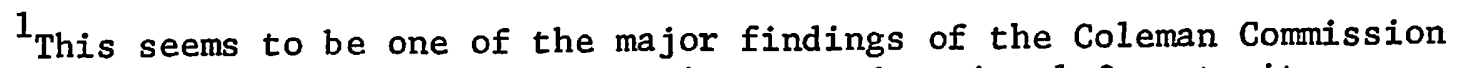
Report. James S. Coleman, et al., Equality in Educational Opportunity, National Center for Educational Statistics (Washington, D.C.: U.S. Government Printing Office, 1966), p. 22.

2 Much of the data I had access to was presented in terms of numbers of teachers per full-time-equivalent student and square feet of space per full-time-equivalent student. Both the Minnesota State College Board and the Minnesota Junior College Board make a great deal of use of planning coefficients expressed in terms of full-time-equivalent students in their formal justifications of their budgetary requests. 
(children of school-starting age), all other factors being merely processed versions of this primary factor. Samuelson has shown that in this sort of a Ricardian system, even though the production functions allow for substitution between factors, such substitution will never in fact take place. ${ }^{1}$

Given the known technology, the competitive market will have already selected the most efficient factor proportions. Changes in the composition of final output or changes in the total supply of the primary factor will not give rise to observable relative price changes or factor substitutions.

The assumption of a fixed-coefficient model is not as restrictive as it appears to be at first glance. By adding new training activities which produce the same output, but use different factor proportions, one can incorporate as much input substitution into the model as he cares to. ${ }^{2}$ Should the educators provide the planner with alternative methods of producing the same training these can be included in the model.

Thus, taking the apparently highly elastic demands for trained labour together with the discrete way in which educators describe their activities, we seem to be on fairly safe ground in using a linear model.

THE BASIC MODEL

The model describes the educational system in a region as an aggregation of production processes or training activities, differentiated by level

${ }^{1}$ Paul A. Samuelson, "Abstract of a Theorem Concerning Substitutability in Open Leontief Models," in Activity Analysis of Production and Allocation, T. C. Koopmans, ed. (New York: John Wiley and Sons, Inc., 1951), pp. 142-46.

2 This is essentially being done when the model is allowed to select among similar activities in different institutions. Each of these curricula is described by an activity that has identical outputs in terms of expected earnings, but different input coefficients. 
and curriculum content. Each of these processes uses a variety of inputs (human, physical and financia1) to transform the beginning or continuing student into a more socially valuable entity. The input requirements of the various activities and therefore, the educational activities themselves, are described by a series of constraints. Some constraints relate to the utilization of inputs supplied from outside the system (public expenditure on education and school-age population), some relate to the utilization of endogenously generated inputs (student outputs of one educational activity that are used as inputs into higher educational activities), and yet others relate to the utilization of inputs that can be both internally generated and imported from outside of the system (teachers of various types). Boundary conditions are added in the form of additional constraints to insure that solutions to the model are administratively feasible and in accord with the abilities and expressed preferences of the student population. Insofar as most of the educational activities in a regional education system are likely to last more than one year, the model, in order to adequately describe the operation of such a system, must be multi-period in nature. In fact, the number of years it covers, the planning horizon, must be at least as long as the longest training activity one seeks to describe. ${ }^{1}$ Thus the solution of the model yields an educational plan represented by a series of projected enrollment levels, a series of requirements for teachers to be trained within the system, a series of requirements for teachers to be recruited from outside the system, the number of student

${ }^{1}$ of course, it is possible in most cases to break the longer courses of study into two or more shorter training activities. Consequently the four years of a college course can be divided into a two-year "lower division" and a two-year "upper division". 
places of different types to be constructed in each year, and the indebtedness the system must incur in each year of the planning period.

\section{The Objective Function}

The objective function measures the net production of social benefits by the educational system, which in turn are measured by the incremental discounted lifetime earnings generated by each activity, less the discounted recurrent cost of operating the activity and the costs of any required additional physical facilities. Activity levels refer to the number of students to be admitted to an activity and the incremental lifetime earnings represents the difference between the lifetime earnings the student could expect commencing with his successful completion of the training activity, and the earning stream he could have expected had he not enrolled in the activity. An adjustment is made for those students who begin an activity but do not complete it. The objective function is additive both in a strictly mathematical sense, in that the net benefits generated by the educational system as a whole are simply the sum of the benefits generated by each activity separately, and more directly, in that the net benefits of educating a student from kindergarten through any given level are the sum of the net benefits generated by the activities required to reach that level. ${ }^{1}$ Turning to the structure of the model itself, the objective function

$1_{\text {The benefits associated with each activity that are the value of }}$ having the option of continuing on to a higher level of education are not included in the objective function. Nonetheless, these benefits are implicitly taken account of in the optimization process due to the hierarchical linkages between activities that are incorporated into the model in the form of the student-flow constraints. In fact, the dual variable associated with each of these constraints is a measure of the "option-value" benefits that would result from a marginal increase in the corresponding student-flow. 
can be expressed as

$$
\begin{aligned}
Z=\sum_{j=1}^{m} \sum_{t=1}^{T}\left[q_{j}\left(Y_{j, t+s_{j}-1}-Y_{j, t-1}^{*}-C_{j t}\right)\right. & \left.+\left(1-q_{j}\right) p_{j}\left(Y_{j, t+s_{j}-1}-Y_{j, t-1}^{*}-C_{j t}\right)\right] X_{j t} \\
& -\sum_{k=1}^{K} \sum_{t=1}^{T} v_{k t} K_{k t}
\end{aligned}
$$

where:

$$
\begin{aligned}
& \mathrm{Z} \text { is the total of net social benefits derived from the educa- } \\
& \text { tional system; } \\
& \mathrm{m} \quad \text { is the number of possible training activities; } \\
& \text { T is the length of the planning period; } \\
& q_{j} \quad \text { is the fraction of those admitted to activity } j \text { who can be } \\
& \text { expected successfully to complete it; } \\
& \mathrm{Y}_{\mathrm{jt}} \quad \text { is the present value (discounted to year one) of the earnings } \\
& \text { stream associated with having completed activity } j \text { in } \\
& \text { year } t \text {; } \\
& \mathrm{Y}_{\mathrm{jt}}^{*} \quad \text { is the present value (discounted to year one) of the earnings } \\
& \text { stream foregone by enrolling in training activity } j \text { in } \\
& \text { year } t \text {; } \\
& s_{j} \quad \text { is the duration of training activity } j \text {; } \\
& c_{j t} \quad \text { is the recurrent cost of operating activity } j \text { for } s_{j} \text { years } \\
& \text { starting in year } t \text {, discounted to year one; } \\
& \mathrm{p}_{\mathrm{j}} \quad \text { is the fraction of the net benefits associated with activity } \\
& \text { j received by dropouts from } j \text {; } \\
& x_{j t} \quad \text { is the number of students admitted to activity } j \text { in year } t \text {; } \\
& \mathrm{K} \text { is the number of different types of school buildings; } \\
& \mathrm{V}_{\mathrm{kt}} \quad \text { is the present value of the capital cost of providing an } \\
& \text { additional student place of type } k \text { in year } t \text {; and }
\end{aligned}
$$


$\mathrm{K}_{\mathrm{kt}} \quad$ is the number of student places of type $\mathrm{k}$ constructed in year $t$.

The coefficient $V_{k t}$ is estimated by using the relationship

$$
V_{k t}=\sum_{\tau=t}^{t+20} r_{\tau} L_{k t}(1+\rho)^{-\tau+1}
$$

$I_{k t}$ is the cost of constructing a student place of type $k$ in year $t, r_{t}$ is the interest rate on funds borrowed in year $t$, and $\rho$ is the discount rate used throughout the objective function. ${ }^{1}$

The objective function, despite its complexity, merely sums the net social benefits associated with admissions to each individual activity included in a particular feasible solution of the model to yield the net social benefits generated by the entire educational system implied by that solution. The first part of the bracketed expression, $q_{j}\left(Y_{j, t+s_{j}}-1^{-Y_{j}^{*}},-1-C_{j t}\right)$, is the social payoff associated with those who successfully complete the activity. The second part, $\left(1-q_{j}\right) p_{j}\left(Y_{j, t+s}-1-Y_{j, t-1}^{*}-C_{j t}\right)$, is the payoff attributable to those who begin, but do not complete, the activity. Notice, it is implicitly assumed that any student could terminate his education with activity $j$ and earn at least $Y_{j}$, regardless of whether or not he entered an occupation directly related to $j$.

The concept of social cost used in the objective function, and hence the definitions of the $C_{j t}$ 's and the $v_{k t}$ 's, should be adjusted to coincide

$1_{\text {Maintenance is assumed to completely offset physical plant deprecia- }}$ tion. Annual maintenance expenses are included in the recurrent cost term, $\mathrm{C}_{\mathrm{jt}} \cdot$. All borrowing by the system is assumed to be in the form of twentyyear bonds. 
with the perspective of the level of government using the model. The state planner may, with some justification, choose to ignore those costs borne directly by the federal government. The planner in the sub-state jurisdiction might choose to omit that portion of the costs paid by both the federal and state governments. The student planner, should he care to play the game, would probably want to omit all costs other than the direct and indirect private costs.

\section{Stock Constraints}

The utilization and augmentation of the educational inputs already at the disposal of the system in the base year are described by a series of stock constraints. These are of two types, those that describe the supply of teachers of different categories and those that describe the supply of building space of various sorts available to the system in each year of the planning period.

The "teacher-stock" constraints have the form

$$
\sum_{j=1}^{m} \sum_{\tau=t+1-s_{j}}^{t} a_{i j t} x_{j \tau} \leq s_{i o}\left(1-d_{i}\right)^{t-1}+\sum_{\tau=1}^{t} R_{i \tau},
$$

where:

$$
\begin{aligned}
& a_{i j t} \quad \text { is the minimum input of teachers of type } i \text { in year } t \text { required } \\
& \text { to accommodate one student in activity } j ; \\
& s_{i o} \quad \text { is the stock of teacher input } i \text { available to the system in } \\
& \text { in the base year; } \\
& d_{i} \quad \text { is the annual natural attrition rate of teachers of type } i \text {; } \\
& \text { and } \\
& R_{i T} \quad \text { is the number of teachers of type } i \text { recruited in year } T .
\end{aligned}
$$


The index $i$ can take values $i=1, \ldots, m+n$, where $n$ is the number of types of teachers not produced internally and which as a result, are only imported. One constraint of this type is required for each category of instructor used in the system for each year of the planning period. Flexibility can be added to the system by adjusting the $a_{i j t}$ 's for wastage due to repeating students. In that case $a_{i j t}=M_{j} T_{j} / s_{j} P_{j}$, where $M_{j}$ is the average number of years required to complete activity $j, T_{j} / P_{j}$ is the teacher-to-pupil ratio required in activity $j$, and $s_{j}$ is the normal duration of activity $j$.

The annual supply of each type of school building used by the system is described by a "building-stock" constraint. These constraints have the form

$$
\sum_{j=1}^{m} \sum_{\tau=t+1-s}^{t} b_{j j} x_{j \tau} \leq s K_{k 0}+\sum_{\tau=1}^{t} K_{k \tau} .
$$

If a "student place" is defined as the number of square feet of type $k$ space required per student in activity $j$, then

$$
b_{k j}=\left\{\begin{array}{l}
1, \text { if activity } j \text { uses building type } k \\
0, \text { otherwise }
\end{array}\right.
$$

However, if a student place is defined in terms of a "work station, ${ }^{1} \mathrm{~b}_{\mathrm{kj}}$ can take on values of less than unity. This will occur if multiple shifts of students use the same work station each day. In fact, $b_{k j}$ will be the inverse of the number of shifts that can use the same work station. The term $\mathrm{SK}_{\mathrm{ko}}$ refers to the stock of student places of type $k$ available in the base year. One building-stock constraint is required for each type of

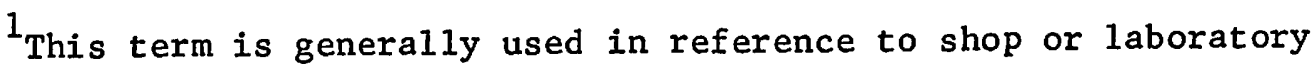
facilities.
} 
building for each year of the planning period.

\section{Flow Constraints}

The movement of students through the educational system, from training activity to training activity, is described by a set of "studentflow" constraints. One constraint is required for each type of continuing student, and one set of these constraints is required for each year of the planning period. A constraint can be defined in terms of either a unique origin or destination activity. These constraints describe the hierachical relationship between training activities; they limit the number of students admitted into any course to the number who have completed the prerequisite training. Each individual student-flow constraint will have the form

$$
\sum_{j=1}^{m} x_{j t} \leq \sum_{i=1}^{m} h_{i} q_{i} x_{i, t-s}
$$

where:

$$
\begin{gathered}
x_{i, t-s_{i}} \begin{array}{r}
\text { refers to the admissions, } s_{i} \text { years before, to a feeder } \\
\text { activity for activity } j ;
\end{array} \\
h_{i}=\left(1-e_{i}\right) \text { and } e_{i} \text { is the historical net percentage of graduates } \\
\text { of } x_{i, t-s_{i}} \text { who leave the system to continue their } \\
\text { education elsewhere. }
\end{gathered}
$$

It is necessary to take account of the fact that students do leave the region to continue their education elsewhere. Had the leakage coefficients, $e_{i}$ not been introduced, it would have been necessary to explicitly

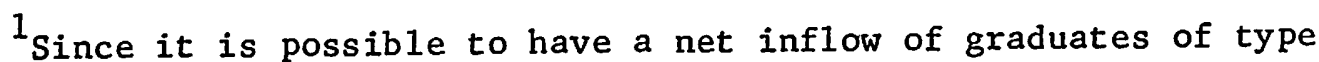
$x_{i, t-s_{i}}$, the coefficient $e_{i}$ may take on a negative value. In this case $h_{i}$ would exceed unity.
} 
include export activities and a set of constraints to prevent all students from being sent out of the region. It turns out that these constraints would always be operational. Any optimal solution would require that as many students be exported as possible, since students who receive their education in an outside institution impose no resource costs on the system. Therefore, given a set of export constraints, each export activity would go to its maximum permissible level. Thus, the size of the exported group would be pre-determined. In addition, the composition of this group would be fixed in terms of level reached and curriculum studied, because the structure of the exported group is determined solely by the relative ranking of the external training activities in terms of the net private benefits they generate. Since the size and composition of this group would remain constant, there would be no variation in the total net social benefits associated with it. As a result, these students are of little interest to the planner once he has established the constraint levels and they can just as well be treated as a net leakage from the system.

Another set of flow constraints is introduced to link the recruitment of teachers both to the internal production of teachers and to the importation of teachers from outside of the system. These constraints are designated "recruitment-flows" and take the following form:

$$
R_{i t} \leq \sum_{i=1}^{m} h_{i} q_{i} X_{i, t-s_{i}}+I_{i t}
$$

$x_{i, t-s_{i}}$ refers to admissions, $s_{i}$ years previously, to an internal training activity producing teachers of type $i . I_{i t}$ refers to the number of teachers of type $i$ who must be imported in year $t$. One of these constraints is required for each type of teacher, and a set consisting of a constraint for each type of teacher is required for each year of the planning 
period. ${ }^{1}$

\section{Exogenous Inputs}

Two additional constraints on exogenously supplied resources are necessary to completely describe the educational system. The first describes the utilization and availability of funds for the construction of new buildings in each year of the plan. The second analogously deals with the educational system's requirements for operational funds and the limitations imposed on their availability. They represent the two types of budgetary constraints placed on the educational system.

The "capital-funds" constraint in each year can be written as

$$
\sum_{k=1}^{K} L_{k t} K_{k t} \leq B_{c t}+D_{t} \text {, }
$$

where:

$B_{c t}$ are the capital funds available in year $t$ from sources other than borrowing, hence, it is the system's capital budget; and

$D_{t} \quad$ represents the amount the system as a whole borrows in year $t$.

The constraint on "operational-funds" has the form

$1_{\text {It }}$ is also possible to formulate the model without explicitly including the recruitment activities, $R_{i t}$. In this case the recruitmentflow constraints can be omitted, linking the teacher-training and teacherimporting activities directly to the teacher-input requirements in the teacher-stock constraints. Unfortunately, this simpler configuration of the model will result in different shadow prices for the same sort of teacher depending on whether the teacher was trained internally or imported. This would detract from the conceptual reality of the model, making the alternative formulation preferable. 


$$
\begin{array}{r}
\sum_{j=1}^{m} \sum_{T=t+1-s_{j}}^{t} a_{f j t} x_{j t}+\sum_{i=1}^{m+n}\left(\sum_{T=1}^{t} W_{i \tau} R_{i \tau}\right)+\sum_{T=-18}^{t} r_{T} D_{T} \leq B_{o t} \\
\\
\quad-\sum_{i=0}^{m+n} W_{i}\left[S_{i o}\left(1-d_{i}\right)^{t-1}\right],
\end{array}
$$

where:

$$
\begin{aligned}
& a_{f j t} \quad \text { is the current annual operating cost of activity } j \text {, less } \\
& \text { teachers' salaries, in year } t ; \\
& W_{i \tau} \quad \text { is the annual wage of teachers of type } i \text { who are initially } \\
& \text { hired in year } T \text {; } \\
& W_{i} \quad \text { is the average annual wage paid to all teachers of type } i \text {; } \\
& r_{t} \quad \text { is the interest rate on bonds issued initially in year } T, \\
& \text { assumed to be at most of twenty year duration; and } \\
& B_{\text {ot }} \quad \text { represents the total amount of operational funds available } \\
& \text { to the system in year } t \text {, from local, state and federal } \\
& \text { sources, less manditory debt retirement. }
\end{aligned}
$$

One constraint of this type is required for each year of the planning period. $^{1}$ The expression $\sum_{i=1}^{m+n} W_{i}\left[S_{i o}\left(1-d_{i}\right)^{t-1}\right]$ refers to the annual drain on operational resources caused by the initial stock of teachers, ${ }^{2}$ whereas

$1_{\text {It }}$ is also possible to formulate the model with budgetary constraints that describe the total amount of financial resources made available to the system over the entire planning period. In this case, the optimization procedure would determine the annual budgets.

2 A possible elaboration of the model would involve the inclusion of teacher-disposal activities. This would allow the immediate removal of redundant teachers from the system, rather than placing reliance solely on natural attrition. However, this modification requires an additional activity and an additional constraint for each type of teacher in each year of the planning period, which greatly increases the size of the model. Nonetheless, depending on the personnel policies of the institutions involved, one procedure is more appropriate than the other. 
the expression $\sum_{i=1}^{m+n}\left(\sum_{T=1}^{t} W_{i T} R_{i \tau}\right)$ refers to the annual wage bill of teachers recruited during the planning period. $\mathrm{W}_{i \tau}$ is essentially the starting salary of type $i$ teachers; as a result, $\sum_{\tau=1}^{t} W_{i \tau} R_{i \tau}$ will seriously understate the true internal costs imposed by newly recruited teachers unless the annual increments in salary are small and the planning period is relatively short. These six types of constraints--the set describing annual teacherstocks, the set describing annual building-stocks, the set describing annual student-flows, the set describing annual teacher-recruitment flows, and the two annual budget constraints--form the core of the model. Their coefficients describe the technology of the educational production processes of which the system is composed.

\section{Boundary Conditions}

Although the model is now, in a sense, structurally complete, the educational system is isolated from its environment, the school-age population. Additional constraints, boundary conditions, must be added to the model to take account of the limited supply of school-age children, their differing levels of innate ability, and their individual preferences for certain courses of study.

In each year of the planning period a constraint is needed to make sure that admissions to the initial training activities do not exceed the external supply of school-age youngsters. If school attendance beginning at a certain age is compulsory, and if the lowest level of education considered in the model corresponds to this age, the constraint imposed by the school-age population takes the form of an equality, $\mathrm{X}_{1 \mathrm{t}}=\mathrm{SAP}_{\mathrm{t}}$. Here $\mathrm{X}_{1 \mathrm{t}}$ refers to this initial training activity (kindergarten or the first grade) and $\mathrm{SAP}_{t}$ refers to the applicable population of school-starting age (five 
or six years, as the case may be) in the region. 1

Any one cohort of students will be very heterogeneous with respect to the students' innate ability, however this may be measured. Insofar as different types and levels of education have prerequisite minimum ability levels, the admissions to the various training activities must be restricted by the differing incidence of these ability levels in a cohort of students. Thus, whenever possible the admissions to an activity must be constrained so as not to exceed the number of students who possess the ability level required for the activity. ${ }^{2}$ If $f_{i j}$ represents the fraction of a cohort that has the ability to go from activity $i$ to activity $j$, then the "ability" constraints take the form

$$
\sum_{j=1}^{m} x_{j t} \leq\left(\sum_{j=1}^{m} f_{i j}\right) q_{i} x_{i, t-s_{i}}
$$

Insofar as each institution generally requires the same ability level for admission to all of its curricula granting the same type of degree, and the

$1_{\text {If the lowest level of training considered in the model does not }}$ correspond to an age at which school attendance is manditory, this constraint takes the form of a weak inequality. In the case where only post-secondary education is included in the model and there are only six grade 13 activities, this constraint would be written as $\sum_{j=1}^{6} x_{j t} \leq \operatorname{SAP}_{t}$, SAP $t_{t}$ being the number of eighteen year olds in the region in year $t$, or preferably the number of highschool graduates in the preceding year.

${ }^{2}$ Ability can be viewed as a student-supplied input into any educationproduction process. Since this input is available in limited supply both in any one student and the population at large, the output of the production process is limited by the availability of this input. The limitation is more binding the less substitution there is between ability and the other inputs. Educators do behave as though fixed coefficients are associated with ability inputs. 
required ability levels differ among institutions, an ability constraint covering all of the admissions to any one institution for study at a given level is needed for each year.

It is characteristic of this sort of programming model to specialize. That is, the optimization procedure will select the activity which has the highest net payoff (objective function coefficient less internal resource consumption) per unit output and expand that activity until it runs into a binding resource constraint, generally operational funds. This leads to a solution that forces all students through the same curriculum, closing down all other training activities as soon as students "in process" can be disposed of. In the model presented here the specialization will not be quite that extreme. The ability constraints should limit admissions to any one institution before the operational-funds constraint becomes operative. As a result, we can expect the activity with the highest net payoff in each institution to be selected, resulting in an educational system where each institution specializes in one curriculum.

It is obvious that such a system which assumes that students go to school solely to maximize lifetime earnings, and which makes little allowance for individual curriculum preferences, no matter how economically perverse they are, will be unacceptable to most parties. Therefore, it seems advisable to introduce a set of constraints that at least places some lower limit on admissions to every activity, keeping every activity operating at some minimal level. This will allow the non-earnings maximizing students some latitude of choice in the selection of their course of study. These lower Iimits should be based on the relative preferences of students for different curricula. Furthermore, it is likely to be undesirable, and perhaps infeasible, from an administrative point of view, to allow drastic increases 
in the enrollment of any activity over a short period of time. Hence, it appears advisable to also place upper limits on the expansion of any activity.

Operationally this involves the introduction of a set of constraints that places upper and lower bounds on the allowable enrollment in each activity in each year of the plan. Each constraint has the form $L B_{j t} \leq x_{j t} \leq U B_{j t}, L B_{j t}$ and $U B_{j t}$ being respectively the lower and upper bounds on activity $j$ in year $t$. Essentially, the lower bounds force a minimal enrollment in each activity, while the upper bounds serve to channel any additional students sequentially into the most profitable ${ }^{1}$ activities. The levels at which these bounds are set will be largely a matter of discretion and therefore, the concern of the policy-maker, not the planner.

\section{Terminal Ad justments}

The addition of these three types of boundary constraints to the six types of structural constraints completes the model. At this juncture it seems appropriate to discuss what adjustments must be made to the model to compensate for the fact that the model deals with a finite time period. Normally it is necessary to introduce "terminal conditions" to prevent activities which can not be completed within the planning period from closing down prior to the terminal year of the plan. However, because of the way the objective function links admissions to projected lifetime earnings, this is not a problem here. On the contrary, because a portion of the resource costs to the system of those activities not completed by the terminal date are not included in the model, these activities become

\footnotetext{
$1_{\text {"Profitability" as defined by the "simplex criterion". }}$
} 
excessively profitably. Although all of the benefits generated by these activities appear in the objective function, their post-terminal-year resource requirements do not appear in the system of constraints. The result is that enrollment will soar in the final years of the plan unless some adjustments are made to the model. The simplest method of compensating for these omitted costs appears to be to multiply the appropriate resourceutilization coefficients in the teacher-stock, building-stock, and operational-funds constraints in the latter years of the model by one plus the number of omitted years in which these enrollees would be trained. At the same time the right-hand side of these constraints must be increased proportionally to facilitate these increased costs. Essentially this simuIates the post-terminal-year costs of each training activity by condensing them into the final years of the model. The number of years for which these adjustments must be made is determined by the duration of the longest training activity. If no activity exceeds two years in length, adjustments need be made only to the final year of the plan.

\section{Application of the Model}

The application of the model ${ }^{1}$ to a particular regional education system is fairly straightforward with respect to the input coefficients in the constraints and the cost coefficients in the objective function. All of the required data supposedly exists, and should be obtainable from the

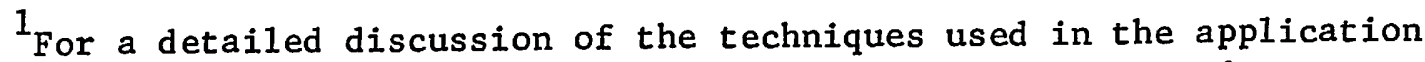
of this model see Peter J. Kuch, "A Planning Model for Post-Secondary Education in West Central Minnesota," an unpublished Ph.D. dissertation, University of Minnesota, 1972. In this study an attempt is made to apply the model to an educational system consisting of six public post-secondary institutions serving a nine-country Development Region in Minnesota. 
institutions themselves, their annual budget requests and the technical reports published by state or provincial agencies.

The ability coefficients, the $f_{i j}$ 's, can be constructed from the distribution of scores on the particular ability cum achievement test that is used by the institutions in the region as a predictor of subsequent academic success.

The estimation of the expected lifetime earnings streams used to calculate the objective function's incremental-earnings coefficients presents greater problems. Ideally, these lifetime-earnings streams should be estimated from time-series data by regressing earnings on curriculum studied and age, while controlling for the effects of such variables as sex, race, innate ability, motivation, on-the-job training, and location. Unfortunately, a suitable body of time-series data that would facilitate such an estimation procedure is not likely to exist. The best alternative course of action would seem to be to make use of census "public-use" samples which contain cross-sectional data on earnings, level of schooling attained, on-the-job training undergone, occupation category, age, sex, race, and place of residence. Using this type of data, the earnings stream estimated for the schooling-occupation combination that is most closely related to a particular curricula would be assumed to be the expected earnings stream that would result from having undergone that training.

Experimentation with the model has indicated that the optimal activity levels obtained for those years in which terminal adjustments have been made will differ somewhat from the activity levels obtained for those same years from a model covering a.longer time-span. ${ }^{I}$ Further refinements of the

${ }^{1}$ Peter J. Kuch, "A Planning Model for Post-Secondary Education in West Central Minnesota," pp. 157-58. 
terminal adjustments are not likely to totally eliminate this problem There are, however, two alternative strategies for using the model that will circumvent it. Let $n$ represent the number of years in which terminal adjustments have been made. The first approach involves extending the time-span of the model, $\mathrm{T}$, $\mathrm{n}$ years beyond the relevant planning period, while the second approach involves sequentially rerunning a model spanning $\mathrm{T}$ years, every $\mathbf{T}-\mathrm{n}$ years.

Since the model is primarily concerned with the selection of an optimal strategy for the investment of public funds in education, private institutions should only be included in the model insofar as they receive a significant amount of public support. In this case they should be incorporated into the model in their entirety and all of the funds they obtain from private sources (tuition, endowments, gifts, etc.) should be added to the annual supplies of resources available to the whole system. Institutions that are essentially independent of public support should be treated as being external to the system, and their students should be treated analogously to those students who leave the region to continue their education els ewhere.

\section{Concluding Comments}

As is inevitably the case, this model has its weaknesses. It ignores all of the non-pecuniary benefits generated by formal education and in general presents an oversimplified view of the processes by which education is produced. Nonetheless, it describes enough of the reality to serve as an effective basic tool for regional education planning.

In gross terms, solutions to the model will indicate which curricula are most efficient at producing a given sort of training. They will also 
indicate which fields of study should be expanded and which should be cut back and what the approximate magnitudes of these changes ought to be. Experimentation with a variety of patterns of future funding levels will indicate the appropriateness of the absolute size of projected budgets and the relationship that the size of the capital budgets should bear to the size of the operating budgets.

The model is useful even in a more basic sense. Its data requirements indicate what basic facts have to be known about the education activities in a region before any sensible decisions can be made about the allocation of resources among these activities. The need to calculate the per student requirements of operating funds, manpower, and physical facilities for each individual program should shift the emphasis of school record-keeping from a departmental basis to a program basis. This in itself would greatly facilitate a more efficient allocation of resources within individual institutions. Finally, this model sets out an approach and a starting point for regional education planning. The model can and should be modified as the state of our knowledge about education progresses. Should subsequent research indicate that earnings levels are negatively related to education output levels, the objective function can be converted to a suitable nonlinear form. As more becomes known about the non-market benefits of various education programs, this information can be incorporated into the objectivefunction coefficients. As more is found out about education production functions and the possibilities for input substitution, the model can be further modified, conceivably by the introduction of non-1inear constraints. 


\section{REFERENCES}

1. Adelman, Irma. "A Linear Programming Model of Educational Planning: A Case Study of Argentina." The Theory and Design of Economic Development. Edited by Irma Adelman and Erik Thorbeck. Baltimore: Johns Hopkins University Press, 1966.

2. Berg, Ivar. Education and Jobs: The Great Training Robbery. New York: Praeger Publishers, 1970.

3. Bowles, Samue1. Planning Educational Systems for Economic Growth. Cambridge, Massachusetts: Harvard University Press, 1969.

4. "Aggregation of Labor Inputs in the Economics of Growth and Planning: Experiments with a Two-Level CES Function." Journal of Political Economy, LXXVIII, No. 1 (January/February, 1970), 68-81.

5. "Towards an Educational Production Function." Education, Income, and Human Capital. Edited by W. Lee Hansen. New York: National Bureau of Economic Research, 1970.

6. Coleman, James S., et a1. Equality of Educational Opportunity. National Center for Educational Statistics. Washington, D.C.: Government Printing Office, 1966.

7. Gintis, Herbert. "Education, Technology and the Characteristics of Worker Productivity." American Economic Review, LXI, No. 2 (May, 1971), 266-79.

8. Griliches, Zvi. "Notes on the Role of Education in Production Functions and Growth Accounting." Education, Income, and Human Capital. Edited by W. Lee Hansen。 New York: National Bureau of Economic Research, 1970.

9. Hanushek, Eric C. "The Education of Negroes and Whites." Unpublished Ph.D. dissertation, Massachusetts Institute of Technology, 1969.

10. Kuch, Peter J. "A Planning Model for Post-Secondary Education in West Central Minnesota." Unpublished Ph.D. dissertation, University of Minnesota, 1972.

11. Miller, Herman P. Income Distribution in the United States. A 1960 Census Monograph. U.S. Department of Commerce. Bureau of the Census. Washington, D.C.: Government Printing Office, 1966.

12. Samuelson, Paul A. "An Abstract Theorem Concerning Substitutability in Open Leontief Models." Activity Analysis of Production and Allocation. Edited by T. C. Koopmans. New York: John Wiley and Sons, Inc., 1951.

13. Welch, Finis. "Education in Production." Journal of Political Economy, LXXVIII, No. 1 (January/February, 1970), 35-59. 